GU J Sci, Part C, 6(4): 774-786 (2018)

Gazi Üniversitesi
Fen Bilimleri Dergisi
PART C: TASARIM VE TEKNOLOJI
http://dergipark.gov.tr/gujsc

\title{
Zaman Pencereli Araç Rotalama Problemi Çözümü İçin Çok Amaçlı Genetik Algoritma Yaklaşımı
}

\author{
Tolunay GÖÇKEN ${ }^{1, *}$, Meltem YAKTUBAY ${ }^{2}$, Fatih KILIÇ³ \\ ${ }^{1,2}$ Endüstri Mühendisliği Bölümü, Adana Bilim ve Teknoloji Üniversitesi, Adana, Türkiye \\ ${ }^{3}$ Bilgisayar Mühendisliği Bölümü, Adana Bilim ve Teknoloji Üniversitesi, Adana, Türkiye
}

\begin{abstract}
$\ddot{O} \mathbf{z}$
Makale Bilgisi

Başvuru: 22/02/2018

Düzeltme: $14 / 08 / 2018$

Kabul: 13/09/2018

\section{Anahtar Kelimeler}

Araç rotalama

Çok-amaçlı optimizasyon

Genetik algoritma

Bu çalışmada, talepleri bilinen müşterilerin, konumu bilinen bir deponun ve belirli sayıda aynı kapasiteye ve özelliklere sahip özdeş araçların bulunduğu klasik Araç Rotalama Probleminin (ARP) bir çeşidi olan Zaman Pencereli Araç Rotalama Problemi (ZPARP) ele alınmıştır. Müşterilere belirli bir zaman aralığında hizmet verilebilen ZPARP için toplam yolu ve araç sayısını minimize etmek amaç fonksiyonları olarak belirlenmiştir. ZPARP'ye etkin çözümler üretilmesi amacı ile meta-sezgisel bir yöntem olan genetik algoritmanın sezgisel metotlarla melezleştirilmiş bir uyarlaması önerilmiştir. Genetik algoritmanın başlangıç popülasyonu oluşturma aşamasında süpürme algoritması ve en yakın komşu tabanlı bir algoritma kullanılarak üretilen kaliteli çözüm kümeleriyle aramaya başlaması, böylece optimum sonuçlara daha hızlı ulaşılması planlanmıştır. Genetik algoritmada başlangıç popülasyonları oluşturmada farklı sezgisel yöntemlerin kullanılmasının istenilen sonuca bir etkisi olup olmadığı test edilmiştir. Literatürde var olan bir veri problemi çözülmüş, süpürme algoritmasını kullanan genetik algoritma ile daha etkin sonuçlara ulaşıldığı görülmüştür.
\end{abstract}

NSGA-II

Süpürme algoritmast

\section{Keywords}

Vehicle routing

Multi-objective

optimization

Genetic algorithm

NSGA-II

Sweep algorithm

\section{A Multi Objective Genetic Algorithm Approach for The Solution of Vehicle Routing Problem with Time Windows}

\begin{abstract}
In this study, Vehicle Routing Problem with Time Windows (VRPTW) which is a type of classical Vehicle Routing Problem (VRP) includes customers with known demands, a single depot with known location and a certain number of identical vehicles with identical capacities and characteristics, is considered. Minimizing the total distance and the number of vehicles are determined as objective functions for VRPTW which is capable to serve the customers in a prespecified time interval. A hybridized version of genetic algorithm with heuristic methods is proposed to produce effective solutions for VRPTW. By using sweep algorithm and nearest neighbor-based algorithm at initial population generation phase of genetic algorithm, it is planned to begin the search with quality solution sets and in this way, get the optimum solutions faster. It has been tested whether the use of different heuristic methods in generation of initial population in genetic algorithm influences the desired solution. A benchmark problem in the literature has been solved and it is observed that the genetic algorithm beginning with sweep algorithm at initial population generation step reaches more effective solutions.
\end{abstract}

\section{GIRIŞ (INTRODUCTION)}

Lojistik yönetimi tedarik zinciri yönetiminin önemli bir parçasıdır. Çeşitli ürünlerin dağıtılması, toplanması veya insanların bir yerden bir yere taşınması gibi her gün karşılaşılan problemlere lojistik yönetimi çerçevesi içerisinde çözüm aranır. Lojistik yönetiminde maliyeti en aza indirmek ve ihtiyaçları hızlı bir şekilde karşılamak asıl amaçtır. Araç Rotalama Problemi (ARP) lojistik alanında yer alan önemli bir yönetim problemidir. ARP, talepleri bilinen müşterilerin talepleri kapasite kısıtlı özdeş araçlarla belirli bir depodan başlanarak ve yine aynı yerde sonlanacak şekilde karşılanırken, araçların kat edeceği toplam mesafeyi minimize eden rotaların belirlenmesi problemidir. Her müşterinin ihtiyacı tek seferde tek bir araç ile karşılanmalı ve aynı rotadaki müşterilerin toplam talep miktarları araç kapasitesini aşmamalıdır. 
Günlük hayatta karşılaşılan bazı durumlar ve problem yapısındaki bazı farklılıklar ARP'nin çeşitlenmesine neden olmaktadır. Birden fazla depo olması, müşteriler arasındaki öncelik ilişkileri, araçların farklı özelliklere sahip olması, müşteri taleplerinin karakteristik yapısı bu durumlardan bazılarıdır. Müşteriler sadece belli bir zaman dilimi içerisinde servis edilebiliyorlar ise problem Zaman Pencereli Araç Rotalama Problemine (ZPARP) dönüşür.

Kombinatorik bir problem olan ZPARP'nin çözümü büyük veri setlerinde kesin optimizasyon teknikleri kullanıldığında çok uzun sürmektedir. Daha kısa çözüm süreleri amaçlandığında sezgisel yöntemler daha kullanışlı olmaktadır. Bu çalışmada meta-sezgisel bir yöntem olan Genetik Algoritma (GA) kullanılmıştır. GA doğadaki evrim mekanizmasına ve doğal seçim ilkelerine dayanan bir optimizasyon yöntemidir. GA döngüsel yapısı sayesinde başlangıç çözümlerini geliştirerek çözüm uzayındaki daha iyi çözümlere ulaşmaya çalışır. Algoritmanın çözüm kümesindeki her nokta kromozomlarla ifade edilmektedir. GA'nın her bir döngüsünde çözümü temsil eden kromozomlarda seçim, çaprazlama ve mutasyon olarak adlandırılan genetik operatörlerin uygulanması sonucu yeni bireylerin üretilmesi ve bu bireyler arasından güçlü bireylerin seçilmesi ile iyi çözüm kümeleri oluşturulmaktadır. Algoritmanın optimum çözüme daha hızlı ulaşabilmesi için başlangıç popülasyonu oluşturma aşamasında farklı teknikler uygulanarak algoritma melezleştirilebilmektedir. Bu çalışmada GA'da başlangıç popülasyonları oluşturmada farklı sezgisel yöntemlerin kullanılmasının istenilen sonuca bir etkisi olup olmadığı test edilmiş ve algoritma ZPARP literatüründe test problemi olan Solomon veri setine uygulanmıştır.

\section{LITERATÜR TARAMASI (LITERATURE REVIEW)}

ZPARP, kombinatorik bir problemdir. Lenstra ve Kan [1] ARP ve ZPARP'nin zorluğunu analiz etmiş ve çözümü zor (NP-Hard) problemler sınıfında yer aldıkları sonucuna ulaşmışlardır. ZPARP için literatürde çeşitli kesin çözüm algoritmaları, sezgisel ve meta-sezgisel yöntemler bulunmaktadır. Dal-sınır (branch and bound), dal-kesme (branch and cut), sütun yaratma (column generation), dinamik programlama ve Lagrangian ayrıştırma yöntemleri kesin çözüm yöntemleri arasında bulunmaktadır. Müşteri sayısının az olduğu durumlar için kesin çözüm algoritmaları kullanılabilir iken, müşteri sayısı arttıkça gerekli bilgisayar hesaplama süresi üstel olarak arttığı için bu yöntemleri uygulamak mümkün olmamaktadır. Bu yüzden son yıllarda araştırmacılar daha çok sezgisel ve meta-sezgisel yöntemler kullanarak problemi çözmeye çalışmaktadırlar [2]. Tasarruf (saving), süpürme (sweep), iki aşamalı yöntem ve geliştirilmiş petal sezgisel algoritmaları klasik sezgisel yöntemler arasında yer alırken; genetik, tabu arama, benzetimli tavlama, karınca kolonisi, yapay arı kolonisi, parçacık sürüsü ve lokal arama algoritmaları meta-sezgisel yöntemler arasında yer almaktadır [3]. ZPARP için çözüm yöntemlerinin daha ayrıntılı literatür tarama çalışmaları [4], [5] ve [6]'da bulunabilir.

GA, ARP ve ZPARP çözümünde sık kullanılan meta-sezgisel yöntemlerden biridir. GA birçok sezgisel yöntem ile melez bir algoritma oluşturmaya imkân veren bir algoritma çeşididir. Klasik veya metasezgisellerle birlikte uygulanabilmektedir. Baker ve Ayechew [7] kapasite kısıtlı ARP için komşu arama algoritması ile birlikte kullanılan melez bir GA geliştirmiştir. Çalışmalarında GA'nın başlangıç popülasyonunu oluşturmak için süpürme ve genelleştirilmiş atama yaklaşımı (generalized assignment approach) algoritmaları kullanılmıştır. Mester ve Bräysy [8], kapasite kısıtlı ARP'nin çözümü için yönlendirilmiş yerel arama (guided local search) ve GA'dan oluşan iki aşamalı tekrarlamalı bir yöntem kullanmıştır. Berger ve Barkaoui [9] ardışık ekleme sezgiselini (sequential insertion heuristic) GA ile birlikte kullanmıştır. Thangiah vd. [10] GIDEON adında biri kümeleme diğeri rotalama işlemi yapan iki ayrı modülden oluşan bir GA sistemi önermişlerdir. Ibrahim vd. [11] En Yakın Komşu sezgiseli ile melezleştirilmiş GA'yı bir şirketin gerçek bir ZPARP olan şişelenmiş su dağıtımı problemine uygulamışlardır. Önerilen algoritma, toplam yol, zaman ve ceza maliyeti bakımından şirketin gerçek hizmet verilerine göre daha iyi sonuçlara ulaşmıştır. Prins [12] ARP için etkili bir evrimsel algoritma önermiştir. Kromozomlarda rota sonlarını belirten bir gösterge kullanmak yerine, kromozomu rotalara ayıran bir bölme algoritması geliştirmiş ve mutasyon aşamasında 9 farklı kural ile yerel arama prosedürünü uygulamıştır. Önerilen algoritma etkili sonuçlara ulaşmıştır. Chang ve Chen [13], Prins'in önerdiği algoritmayı ZPARP'ye uygulamışlardır. Ele aldıkları problemde zaman penceresi olarak sadece servise başlama zamanının belirtildiği ve araçların kapasite sınırı olmadığı varsayılmıştır. Algoritma, 3 farklı popülasyon büyüklüğü ve 3 farklı mutasyon olasılığ belirlenerek 2 farklı veri setinde test edilmiştir. Mutasyon olasılı̆̆ 
arttıkça, genel olarak, hata oranının ve rota sayısının azaldığı gözlenmiştir. Ayrıca popülasyon büyüklüğü ve mutasyon olasılığ 1 artıkça daha iyi sonuçlar elde edilmiştir.

Ombuki, Ross ve Hanshar [14] ZPARP için Pareto sıralama tekniği kullanarak çok amaçlı GA yaklaşımı sunmuşlardır. Amaç olarak araç sayısını ve toplam maliyeti minimize etmek belirlenmiştir. Pareto değerlendirmesi sayesinde amaçların ağırlıklandırılmasına ve ağırlıklı toplam yönteminin kullanılmasına ihtiyaç kalmamıştır. Bu yaklaşımla etkili sonuçlara ulaşılmıştır. Haddadene, Labadie ve Prodhon [15] evde sağlık bakımı alanında zaman penceresi, senkronizasyon ve öncelik kısıtlı ARP çözümü için melez bir NSGA-II (Non-dominated Sorting Genetic Algorithm II) (Mağlup Olmayan Siralamalı Genetik Algoritma II) yöntemi önermişlerdir. Problem amaçları seyahat maliyetini minimize etmek ve hasta memnuniyetini maksimize etmek olarak belirlenmiştir. Temel NSGA-II ile melez NSGA-II karşılaştırması yapılmış ve yerel arama tabanlı melez NSGA-II daha iyi sonuçlara ulaşmıştır. Tan, Chew ve Lee [16] bazı sezgiseller ve özelleştirilmiş genetik operatörler ile birleştirilen melez çok amaçlı evrimsel algoritma geliştirmişlerdir. Toplam yolu ve araç sayısını minimize etmeyi amaçlamışlardır. Geliştirilen algoritma iyi sonuçlar üretmiştir. Mungwattana vd. [17] GA, değiştirilmiş ilerletici ekleme sezgisel yöntemi (MPFIH) ve $\lambda$ değiştirme yerel arama azaltma yöntemi ( $\lambda$-LSD) kullanarak esnek ZPARP için bir çözüm yöntemi önermişlerdir. Araç sayısını ve toplam seyahat süresini minimize etmeyi amaçlar olarak belirlemişlerdir. Önerilen algoritma genel olarak etkili sonuçlar sağlamıştır. Ghoseiri ve Ghannadpour [18] hedef programlama ve GA kullanarak ZPARP çözümü için bir model önermişlerdir. Araç filosu büyüklügünü ve toplam seyahat süresini minimize etmeyi amaçlar olarak belirleyerek problemi çok amaçlı olarak ele almışlardır. Modellerinde bazı sezgisellerle beraber, Pareto sıralama tekniğini ve elitizm stratejisini kullanmışlardır ve oldukça etkili sonuçlara ulaşmışlardır. Najera ve Bullinaria [19] ZPARP için çok amaçlı evrimsel algoritma kullanarak bir çözüm önerisi sunmuşlardır. Önerdikleri algoritmada Pareto sıralama tekniğini ve benzerlik ölçüm metodunu uygulamışlardır. Algoritma yüksek rekabetçi sonuçlara ulaşmıştır.

\section{PROBLEM TANIMI (PROBLEM DEFINITION)}

ARP bir grup müşteriye hizmet verecek araçlara en uygun rotaların belirlenmesi problemidir. Müşterilerin sayısı, konumları ve talep miktarları belirlidir. Problemde konumu bilinen ve ürünleri toplama merkezi olan bir tane depo bulunur. Her araç, rotasına depodan başlamak ve rota sonunda depoya dönmek zorundadır. Araçlar belirli sayıdadır ve aynı özelliklere sahiptirler. Özdeş araçların kapasite kısıtları bulunmaktadır. Bir aracın takip edeceği rotada hizmet sunacağı müş̧erilerin talep miktarları toplamı araç kapasitesini aşmamalıdır. Her müşteriye sadece bir araç hizmet sunmalı ve tek seferde talebi karşılamalıdır. Sadece araç kapasite kısıtı bulunan ARP, Kapasite Kısitlı ARP olarak anılır.

ZPARP'de Kapasite Kısıtlı ARP'de olduğu gibi aynı karakteristik özelliklere sahip araçlar, müşteriler ve bir tane depo bulunmaktadır. Bu problem türünü diğerlerinden ayıran ve problemi daha da güçleştiren kısıt, her müşteri için servise başlanabilecek belirli bir $\left(\mathrm{e}_{\mathrm{i}}, \mathrm{l}_{\mathrm{i}}\right)$ zaman aralığının olmasıdır. Bu zaman aralığı her müşteri için tanımlanmış olan zaman pencere kısıtıdır. Her müşteriye kendi zaman penceresi içerisinde hizmete başlanması gerekmektedir. Her müşteriye dağıtım yapmak ya da hizmet sunmak belirli bir $\mathrm{s}_{\mathrm{i}}$ servis süresi kadar zaman gerektirir. Araç i müşterisine uğradıktan sonra $s_{i}$ hizmet süresi kadar kalacaktır, daha sonra bir sonraki müşteriye ya da depoya hareket edecektir. Servis maliyeti tüm müşterilerin servisi için gerekli araç sayısı ve araçların aldığı toplam mesafe ile ölçülür [20]. Problemdeki amaç maliyeti en küçüklemektir.

ZPARP zaman pencere kısıtının sıkı veya esnek olma durumuna göre ikiye ayrılır. Sıkı zaman pencereli ARP'de müşterilerin zaman aralıkları dışında hizmet verilmemektedir. Araç müşteriye zaman aralığının başlangıcından önce ulaşmışsa beklemek zorundadır, zaman aralığı bitiminden sonra da hizmet verememektedir. Esnek zaman pencereli ARP'de zaman pencere kısıtı ceza maliyeti karşılığında ihlal edilebilmektedir [21]. Bu çalışmada, sıkı zaman pencereli ARP ele alınmıştır.

ZPARP için amaçlar şu şekilde olabilir:

- Toplam yolu minimize etmek,

- Toplam seyahat süresini minimize etmek,

- $\quad$ Araç sayısını minimize etmek, 
- Araçların bekleme sürelerini minimize etmek, ve

- Araçların alan kullanımını maksimize etmek.

Bunlardan biri veya birkaçı amaç olarak seçilebilir. Amaçların minimuma ulaşmak olduğu durumlarda birini azaltmaya çalışmanın diğerinde artışa sebep olması birbirleriyle çelişkili olduklarını gösterir. Çok amaçlı optimizasyon yaparken daha etkin sonuçlara ulaşabilmek için seçilen amaçların birbirleriyle çelişkili olması önemlidir. Bu sayede çözüm uzayı araştırılırken amaçların eş zamanlı olarak optimize edilmesi anlamlı olur. Bu çalışmada toplam yolu ve araç sayısını minimize etmek amaç fonksiyonları olarak belirlenmiştir ve problem çok amaçlı optimizasyon problemine dönüştürülmüştür.

Problem kısıtları ise şu şekildedir:

- Rotalar deponun zaman penceresi içerisinde depoda başlayıp yine depoda bitmelidir.

- Her müşteri tek bir araçla tek seferde hizmet görmelidir.

- Aynı rotadaki müşterilerin toplam talep miktarları araç kapasitesini aşmamalıdır.

- Müşteriler zaman pencereleri içerisinde hizmet görmelidir. Erken gelen araçlar müşterinin hazır olma zamanını beklemek durumundadır.

ZPARP'nin matematiksel modelini oluşturmada kullanılan karar değişkenleri, parametreler ve kümeler aşağıdaki gibidir.

Karar değişkenleri:

$$
\begin{array}{cl}
x_{i j k} & \left\{\begin{array}{r}
1, \mathrm{k} . \text { araç i müşterisinden j müşterisine gidiyorsa } \\
0, \text { aksi takdirde }
\end{array}\right. \\
t_{i} & \text { i müşterisine varış zamanı } \\
w_{i} & \text { i müş̧erisinde bekleme süresi }
\end{array}
$$

Parametreler:

$$
\begin{array}{cl}
d_{i j} & \text { i müşterisi ve j müşterisi arasındaki mesafe } \\
s_{i} & \text { i müşterisinin servis süresi } \\
e_{j} & \text { j müşterisinin zaman aralığının başlangıç zamanı } \\
l_{j} & \text { j müşterisinin zaman aralığının bitiş zamanı } \\
l_{0} & \text { Deponun zaman aralığının bitiş zamanı (Bir aracın maksimum seyahat süresi) } \\
m_{i} & \text { i müşterisinin talep miktarı } \\
Q & \text { Özdeş araçların kapasitesi }
\end{array}
$$

Kümeler:

$$
\begin{array}{ll}
C & \{1,2, \ldots, n\} \text { Müşteri kümesi } \\
N & \{0,1,2, \ldots, n\} \text { Düğüm kümesi (0. düğüm depoyu ifade etmektedir.) } \\
V & \{1,2, \ldots, v\} \text { Araç kümesi }
\end{array}
$$

ZPARP'nin matematiksel modeli aşağıdaki gibidir:

Amaç fonksiyonları:

Minimum

$$
\begin{aligned}
& \sum_{i=0}^{n} \sum_{j=0}^{n} \sum_{k=1}^{v} d_{i j} * x_{i j k} \\
& \sum_{k=1}^{v} \sum_{j=1}^{n} x_{0 j k}
\end{aligned}
$$

Şu kısıtlara göre: 


$$
\begin{aligned}
& \sum_{k=1}^{v} \sum_{j=1}^{n} x_{0 j k} \leq v \\
& \sum_{j=1}^{n} x_{0 j k}=\sum_{j=1}^{n} x_{j 0 k} \leq 1, \quad \forall k \in V \\
& \sum_{k=1}^{v} \sum_{i=0}^{n} x_{i \neq j} x_{i j k}=1, \quad \forall j \in C \\
& \sum_{k=1}^{v} \sum_{j=0, j \neq i}^{n} x_{i j k}=1, \quad \forall i \in C \\
& \sum_{i=1}^{n}\left(m_{i} * \sum_{j=0, j \neq i}^{n} x_{i j k}\right) \leq Q, \quad \forall k \in V \\
& \sum_{i=0}^{n} \sum_{j=0, j \neq i}^{n} x_{i j k}\left(d_{i j}+s_{i}+w_{i}\right) \leq l_{0}, \quad \forall k \in V \\
& t_{0}=w_{0}=s_{0}=0 \\
& t_{i}+w_{i}+s_{i}+d_{i j}=t_{j}, \quad \forall(i, j) \in N, i \neq j, i f x_{i j k}=1 \\
& \left.w_{i}=\max _{\{} e_{i}-t_{i}, 0\right\}, \quad \forall i \in C \\
& e_{j} \leq\left(t_{j}+w_{j}\right) \leq l_{j}, \quad \forall j \in C \\
& x_{i j k} \in\{0,1\}, \quad \forall k \in V, \forall(i, j) \in N \\
& t_{i} \geq 0, \quad \forall i \in C \\
& w_{i} \geq 0, \quad \forall i \in C
\end{aligned}
$$

Amaç fonksiyonlarından Eş. 1 toplam yolu ve Eş. 2 kullanılan araç sayısını minimize etmeyi amaçlar. Eş. 3 kısıtı depodan çıkabilecek maksimum araç sayısının v olmasını sağlar ve böylece tüm araçların kullanım zorunluluğu ortadan kalkar. Eş. 4 kısıtı her rotanın depodan başlayacağını ve depoda biteceğini belirtir. Eş. 5 ve Eş. 6 kısıtları her müş̧eriye sadece tek bir aracın servis sunmasını sağlar. Eş. 7 kısıtı bir rotadaki müşterilerin toplam talep miktarlarının araç kapasite sınırını aşmasına engel olur. Eş. 8 -12 problemin zaman pencere kısıtını sağlar. Eş. 8 kısıtı maksimum seyahat süresi kısıtıdır. Eş. 9, Eş. 10'da i düğümünün 0 olması durumunda depo için kullanılacak karar değişkenlerinin ve bir parametresinin değerlerini gösterir. Eş. 10, müşteri i'den müşteri j'ye gidiliyorsa, müşteri j'ye varış zamanının müşteri i'ye varış zamanından i'deki bekleme süresi, servis süresi ve i'den j'ye gidiş süresi kadar sonra olduğunu ifade eder. Araçların 1 birim mesafeyi 1 birim zamanda gittikleri varsayıldığından elde edilen mesafe değeri süre olarak da kullanılabilir. Eş. 11 kısıtı eğer araç müşterinin hazır olma zamanından önce gelmişse bekleme süresinin hesaplanmasını sağlar. Eş. 12 kısıtı müşteriye sunulacak hizmetin ilgili müşterinin zaman aralığı içinde başlamasını sağlar. Eş. 13 -15 kısıtları karar değişkenlerinin alabileceği değer kümelerini belirtir. Bu model ZPARP için uygulanabilir çözümlere ulaşılmasını sağlar.

\section{4. ÖNERILEN ALGORITMA (PROPOSED ALGORITHM)}

\subsection{Başlangıç Algoritmaları (Initial Algorithms)}

\subsubsection{Algoritma I (Algorithm I)}

GA'nın ilk aşaması, her bireyin bir çözümü temsil ettiği bir çözüm kümesi olan başlangıç popülasyonunu oluşturmaktır. Bu çalışmada kullanılan ilk başlangıç popülasyonu oluşturma algoritması En Yakın Komşu algoritması temel alınarak oluşturulmuştur. En Yakın Komşu algoritması bir rotaya eklenmiş en son müşterinin ardına bu müşteriye mesafe açısından en yakın olan başka bir müşteriyi eklemektedir. Ancak problemde zaman pencere kısıtı olduğundan rotaya atanacak müşterinin seçimine sadece mesafeye bakarak karar vermek istenilen çözüme ulaşmada yeterince etkili olamamaktadır. Bu nedenle depodan başlayarak bir rotaya atanacak ilk müşterinin seçiminde müşterinin depoya uzaklığı ile o müşterinin servise hazır olma süresi karşılaştırılır, ilgili müşteriye bu değerlerden büyük olanı seçim değeri olarak atanır. Bir birim uzaklık, bir birim zaman diliminde gidildiği varsayıldığ 1 için karşılaştırma rahatlıkla yapılabilir. Bütün müşteriler arasından seçim değeri minimum olan müşteri ilk rotanın ilk müşterisi olarak seçilir. Bir rotaya eklenmek üzere seçilen her müşteri, müşteri listesinden kaldırılır ve araç kapasitesinin doluluğu hesaplanır. Sıradaki müşterinin seçimi için rotalanan son müşterinin müşteri listesindeki rotalanmayan müşterilere uzaklıkları hesaplanır. Servis süresi dikkate alınarak olası müşterilerin servise başlama süreleri hesaplanır ve zaman pencere kısıtını sağlayan müşteriler arasında bir değerlendirme yapılır. Müşteriler arasında seçim 
değeri küçük olanın rotaya alınma olasılığı yüksek olacak şekilde rastgele bir seçim yapılır. Seçilen müşteri rotaya eklenir ve müşteri listesinden kaldırılır. Araç kapasitesi dolana kadar müşteriler aynı şekilde rotaya alınmaya devam edilir. Araç kapasitesinin aşıldığı durumda aracın depoya dönmesi için rota sonuna depo eklenir ve yeni bir rotaya başlanır. Rota çözümleri rota kümesine eklenir. Müşteri listesinde müşteri kalmayınca rotalarda iyileştirme yapılır. En Yakın Komşu tabanlı olarak oluşturulan Algoritma 1'in aşamaları Tablo 1'de gösterilmiştir.

Tablo 1. En Yakın Komşu Tabanlı Algoritma

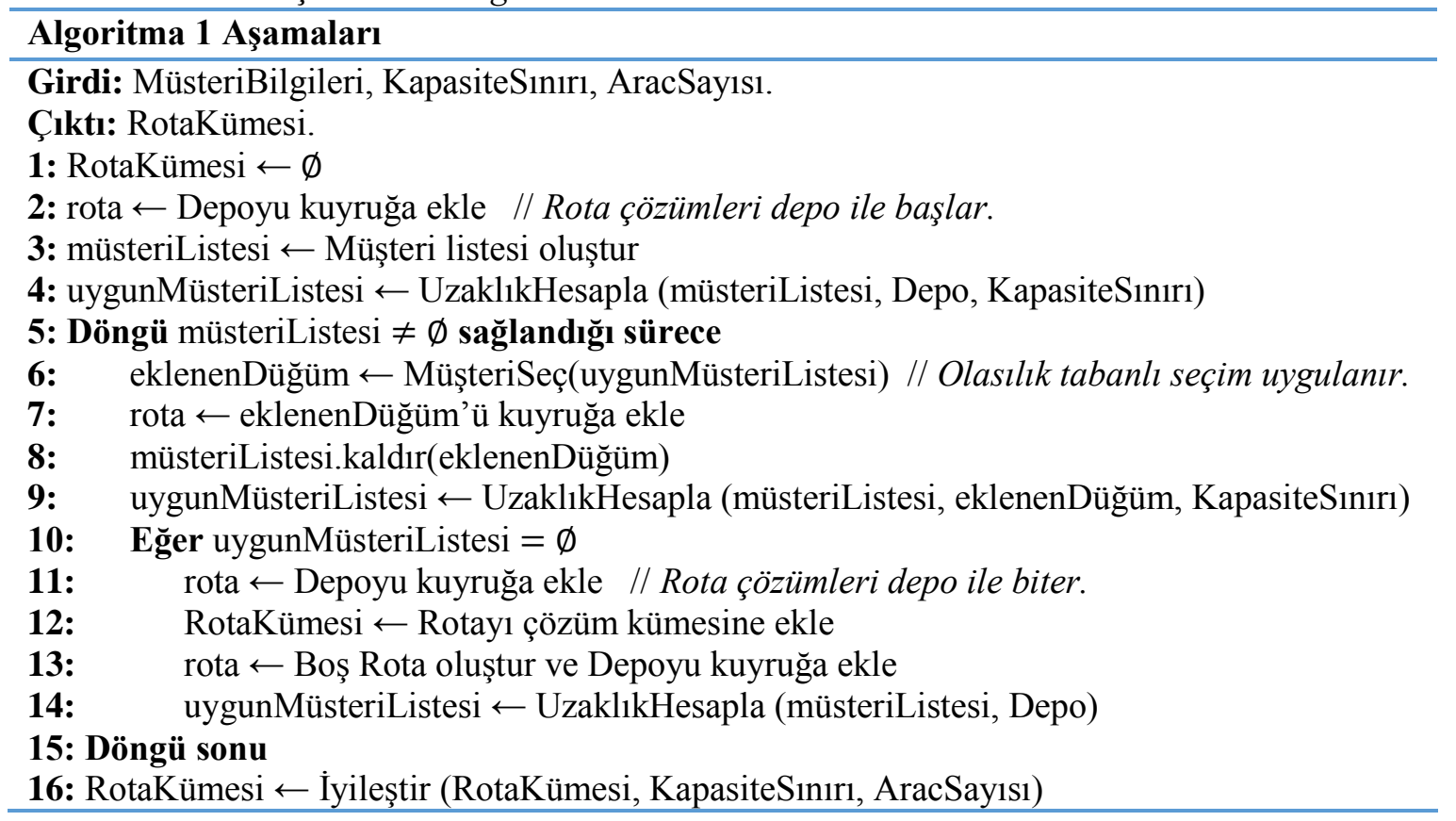

\subsubsection{Algoritma II (Algorithm II)}

1974 y1lında Gillett ve Miller [22] tarafindan önerilen Süpürme algoritması bu çalışmada başlangıç popülasyonu oluşturmada ikinci algoritma olarak kullanılmıştır. Süpürme algoritmasında (x, y) koordinatları bilinen müşterilerin polar açıları, orijin kabul edilen depoya göre Eş. 16' da gösterildiği gibi hesaplanır:

$$
A n(i)=\arctan \left[\frac{(y(i)-y(0))}{(x(i)-x(0))}\right]
$$

Hesaplanan polar açılar küçükten büyüğe doğru sıralanır. Şekil 1'de gösterildiği gibi, orijinden başlayan ve rastgele belirlenen bir açıdan çıkarılan ışın saat yönünün tersi yönünde döndürülerek süpürme işlemi gerçekleştirilir. Bu esnada ışının üzerinden geçtiği müşteriler sıra takip edilerek bir araca atanır. Atama işlemi araç kapasitesi dolana kadar devam eder, kapasite kısıtı aşıldığı durumlarda atamaya kullanılmamış bir araç ile devam edilir. Bu şekilde müşteriler kümelenmiş olur. Kümelenen müşterilere depo dahil edilerek rotalama işlemi yapılır. Rotaya ilk olarak depo atanır ve aynı kümedeki müşterilerden depoya uzaklığı en kısa olan rotaya eklenir. Rotaya eklenen müşterinin rotalanmayan müşterilere uzaklığı hesaplanır ve zaman kısıtını ihlal etmediği sürece en yakın olan rotaya alınır. Bu şekilde tüm kümelerdeki müşteriler için birer rota oluşturulur. Rotalanamayan müşterilerin olması durumunda, mevcut rotalara kisıtların ihlali olmayacak şekilde eklenebilecekler eklenir. Uygun bir yer bulunmazsa yeni bir rota oluşturulur. Tüm rotalarda iyileştirme yapılır. Süpürme Algoritması tabanlı oluşturulan Algoritma 2'nin aşamaları Tablo 2'de gösterilmiştir. 


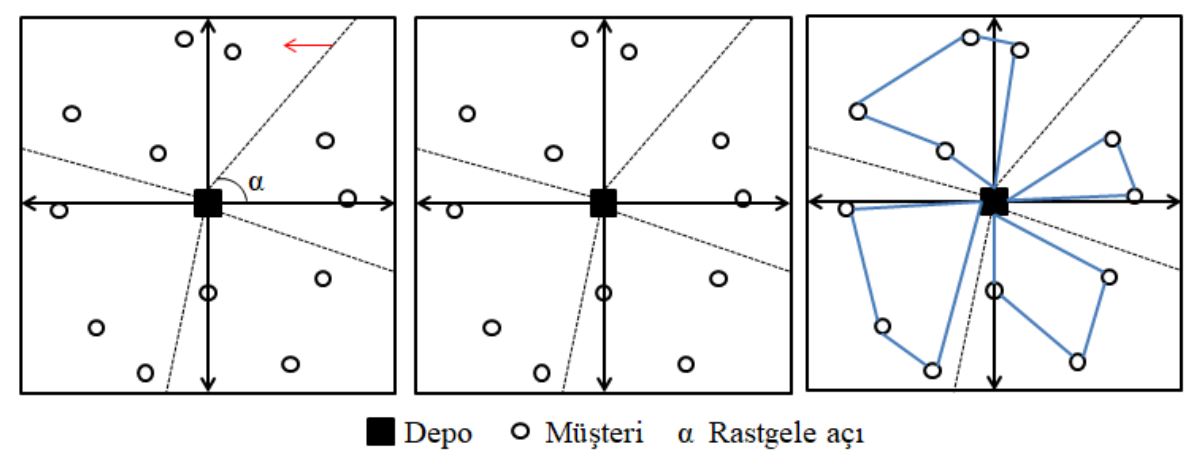

Şekil 1. Süpürme Algoritmast

Tablo 2. Süpürme Tabanll Algoritma

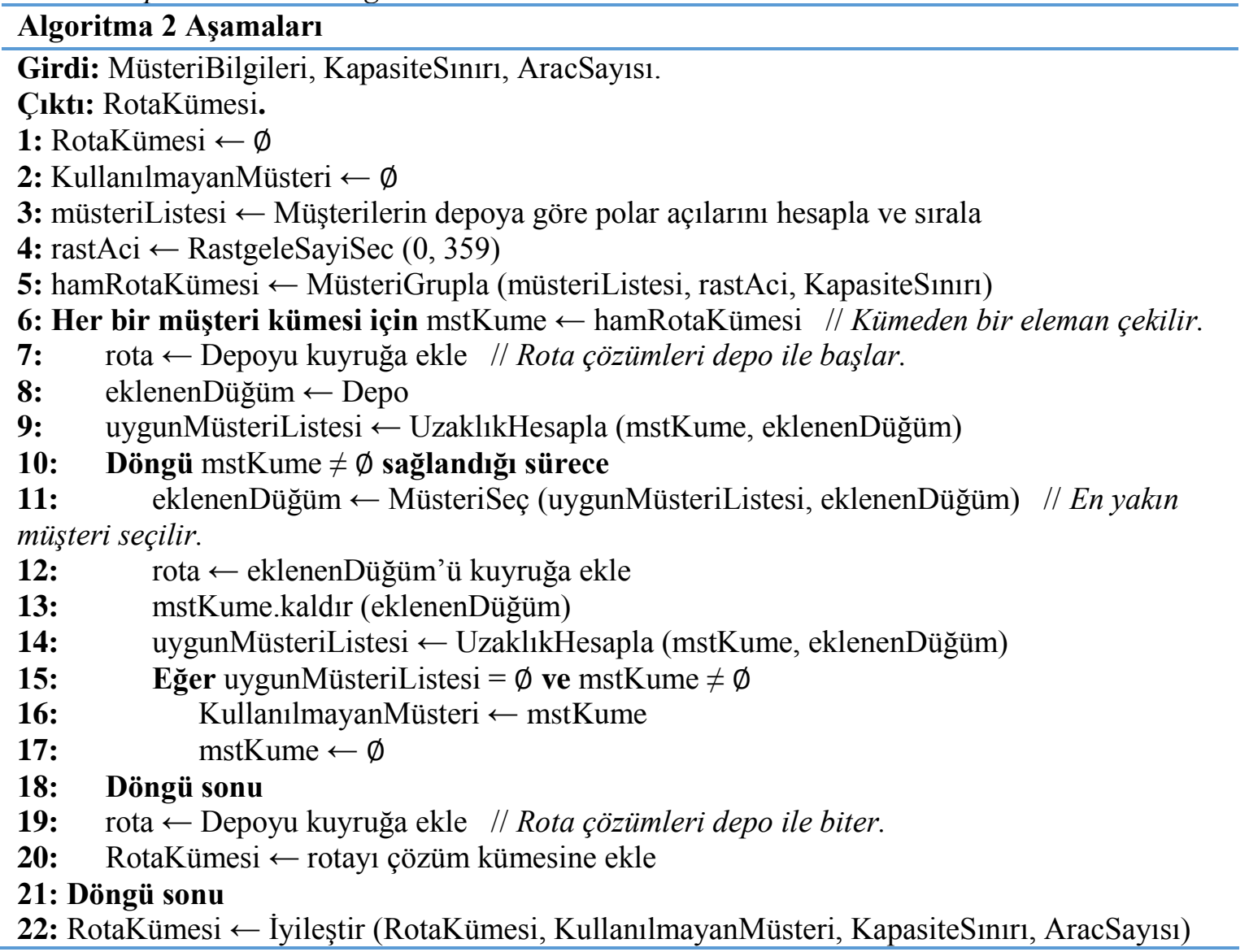

\subsection{Genetik Algoritma (Genetic Algorithm)}

GA'da çözümü aranan problem için olası tüm çözümler birey (kromozom) olarak adlandırılır ve her bir birey çözümü oluşturan parametrelerden oluşmaktadır. Bireylerden oluşan çözüm kümesi popülasyonu oluşturmaktadır. Başlangıç popülasyonunun üretilmesinden sonra her bir çözümün amaç fonksiyon değeri hesaplanmaktadır. Amaç fonksiyon değeri olası çözümün istenen çözümü ne kadar karşıladığının bir ölçüsüdür. Amaç fonksiyon değeri problemde belirlenen ölçütü sağlıyorsa algoritma sonlandırılır, aksi halde seçim, çaprazlama ve mutasyon işlemleri uygulanarak optimizasyon ölçütü sağlanana veya önceden belirlenmiş olan bir iterasyon sayısına ulaşıncaya kadar algoritma devam ettirilir [23].

Kılıç ve Gök [24] 2015'teki çalışmalarında geliştirdikleri GA'yı toplu taşıma araçlarının rotalarının belirlenmesi probleminde kullanmışlardır. Bu çalışmada ise geliştirilen GA ZPARP'ye çözüm üretmek için kullanılmıştır. ZPARP çözümü için uyarlanan GA'nın temel adımları Tablo 3’te verilmektedir. 
Tablo 3. Genetik Algoritma

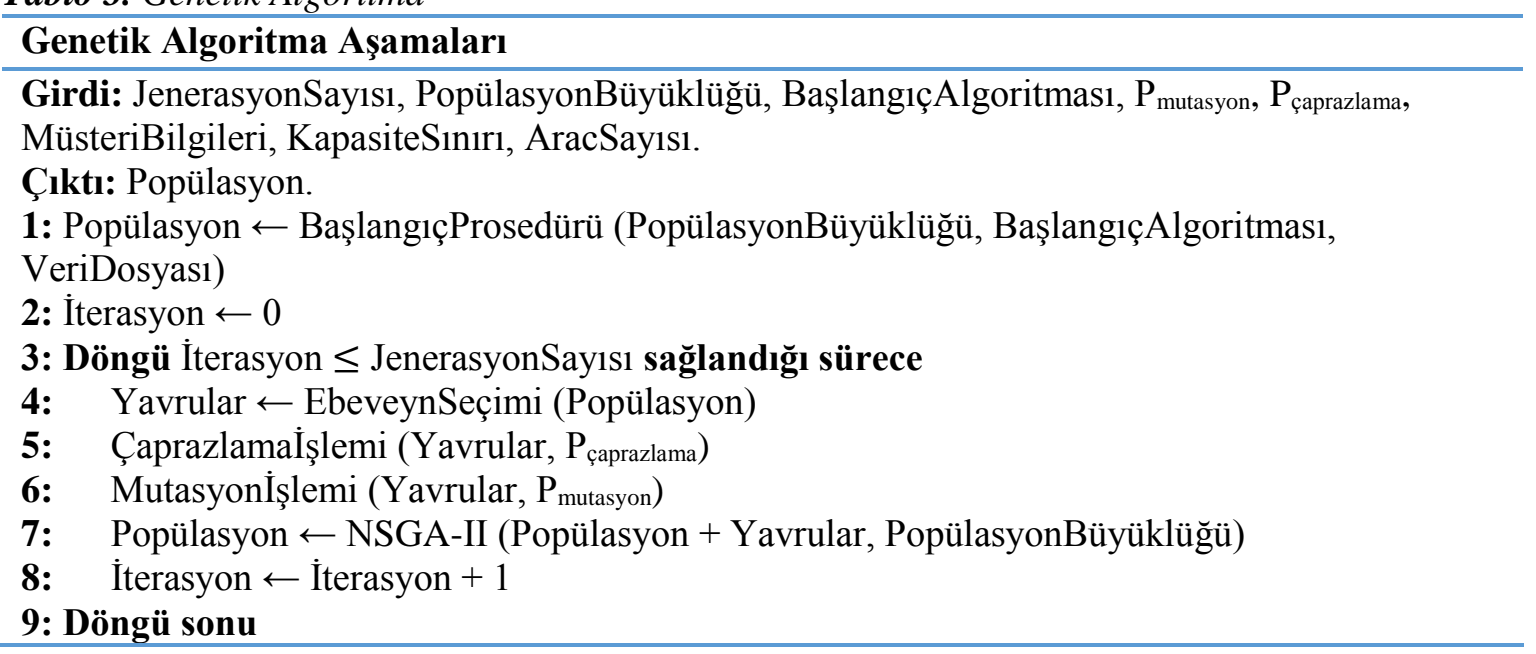

Popülasyondaki her birey permütasyon kodlaması kullanılarak gösterilmiştir. Permütasyon kodlamada müşteri numaraları araç tarafindan servis edilme sırasına göre dizilmektedir. Başlangıç popülasyonları önceki bölümde anlatılan algoritmalar kullanılarak üretilmiştir. Yavruların üretimi için ebeveyn seçim aşamasında bireylerin baskınlık durumları dikkate alınmıştır. Çok amaçlı optimizasyon yapıldığı için baskınlık sıralamasına Pareto optimal cepheler kullanılarak karar verilmiştir. Baskın olma durumlarına göre sıralanan bireyler ardışık olarak ikişerli eşleştirilmiştir. Çaprazlama işlemi için çift noktalı çaprazlama yöntemi kullanılmıştır. Genetik çeşitliliği korumak ve çözümlerin yerel optimuma düşmesini engellemek adına komşu çözümleri bulmak amacıyla mutasyon işlemi uygulanmıştır. Mutasyon operatörü olarak yer değiştirme yöntemi şu şekilde gerçekleştirilmiştir. Üretilen yavru bireyden rastgele bir rota, rotadan da rastgele bir müşteri seçilip kaldırılır. Çözümden çıkarılan müşteri amaç fonksiyonunu minimum yapacak şekilde en uygun yere yerleştirilir. Son olarak bir sonraki popülasyonu oluşturacak bireylerin seçimi için NSGA-II kullanılmıştır. NSGA-II için DEAP Kütüphanesinden yararlanılmıştır [25, 26, 27].

NSGA-II hızlı ve elitist (seçkinci) çok amaçlı bir optimizasyon çözüm yöntemidir. NSGA-II ile bir popülasyonun oluşturabileceği Pareto cephelerin tüm noktaları belirlenebilmekte ve tüm bireyler baskınlıklarına, başka bir deyişle mağlup olmamalarına, göre sıralanabilmektedir. Bir birey başka bir bireye şu durumlarda baskın olur: Her bir amaç fonksiyonu değeri diğerinin değerinden daha kötü değildir. Ve en az bir amaç fonksiyonu değeri diğerinden daha iyidir [28]. Bir en küçükleme probleminde a bireyinin $b$ bireyine baskın olması, başka bir deyişle a bireyinin b bireyine mağlup olmaması, aşağıda gösterilen durumlarda sağlanır:

$$
a \leq b(\text { a baskın } b) \Leftrightarrow \forall_{i}: a_{i} \leq b_{i}, \exists_{i}: a_{i_{0}}<b_{i_{0}}
$$

Popülasyondaki bütün bireyler her bir amaç fonksiyonu için birbirleriyle karşılaştırılır. Her bireyin 1) mağlup olduğu birey sayısı bir sayaç yardımı ile hesaplanır ve 2) mağlup ettiği bireyler kümesi oluşturulur. Sayaç değeri 0 olan bireyler ilk cephede (first nondominated front) yer alırlar. İlk cephedeki bireylerin rütbeleri (rank) 1 olur. Daha sonra rütbeleri 1 olan bireylerin mağlup ettiği bireyler kümesindeki her elemanın sayaç değeri 1 azaltılır. Sayaç değeri 0 olan bireyler ikinci cepheyi oluştururlar ve rütbeleri 2 olur. $\mathrm{Bu}$ işlem bütün cepheler tanımlanıncaya kadar devam eder. Düşük rütbelerin önemi fazladır ve bireylerin sıralaması düşük rütbeliden yüksek rütbeliye doğru olur.

Bireyler aynı cephede yer alıyorsa, bireylerin önem sırasını belirlemek için ikinci bir ölçüte ihtiyaç duyulmaktadır. Bu nedenle yoğunluk mesafesi veya yığılma uzaklığg (Crowding Distance) olarak ifade edilen bir kavram kullanılmaktadır. Yoğunluk mesafesi, ilgili bireyin her amaç için komşuluklarına olan uzaklığın toplamıdır ve Eş. 17'de gösterildiği gibi hesaplanır:

$$
C D_{i}=\sum_{m=1}^{n} \frac{\left|f_{i+1}^{m}-f_{i-1}^{m}\right|}{f_{\max }^{m}-f_{\min }^{m}}
$$

CD: yoğunluk mesafesini, n: toplam amaç sayısını, f: amaç fonksiyon değerini ifade etmektedir. $f_{\max }^{m}$ ve $f_{\min }^{m} \mathrm{~m}$. amaç fonksiyonunun ilgili cephedeki en büyük ve en küçük olduğu değerlerdir. Amaç 
fonksiyonunun en büyük ve en küçük olduğu değerler ilgili cephenin sınır bireylerine aittir ve sınır bireylerinin sonsuz yoğunluk mesafesine sahip olduğu kabul edilir. Sınır bireyler arasında kalan bireylerin yoğunluk mesafeleri hesaplanır. Küçük yoğunluk mesafesine sahip bireyler diğer çözümlere daha yakındır. Çözümler arasında karşılaştırma yapılırken yüksek mesafeye sahip olanlar, başka bir deyişle yoğunluktan uzak olanlar, tercih edilir.

Bir sonraki popülasyonu oluşturacak bireylerin seçimi için Şekil 2'de gösterildiği gibi o döngüdeki popülasyon ve oluşturulan yavru popülasyonu birleştirilir. Bu sayede bir popülasyondaki en iyi bireylerin korunarak sonraki nesle aktarılması, yani elitizm (seçkincilik) sağlanır. Her popülasyonda $\mathrm{N}$ adet birey bulunur ve tekrar $\mathrm{N}$ adet birey seçilecektir. $2 \mathrm{~N}$ adet birey mağlup olmayan sıralama yardımıyla baskınlıklarına göre sınıflandırılır. Oluşturulan cephelere göre rütbesi 1 olan bireylerden başlanarak seçme işlemi yapılır. 1., 2., 3., 4. cepheler şeklinde ilerleyerek bireyler sırayla popülasyona alınır. Toplam birey sayısı popülasyon büyüklüğünü aştığı durumda alınan son cephedeki bireylerde yoğunluk mesafesi karşılaştırması yapılır. Buna göre ilgili cephedeki bireylerin yoğunluk mesafesi değerleri büyükten küçüğe doğru sıralanır ve yeni popülasyonu dolduracak sayıdaki bireyler yeni popülasyona seçilir. Bu şekilde bir sonraki popülasyon oluşturulmuş olup tekrar GA prosedürü işletilir.

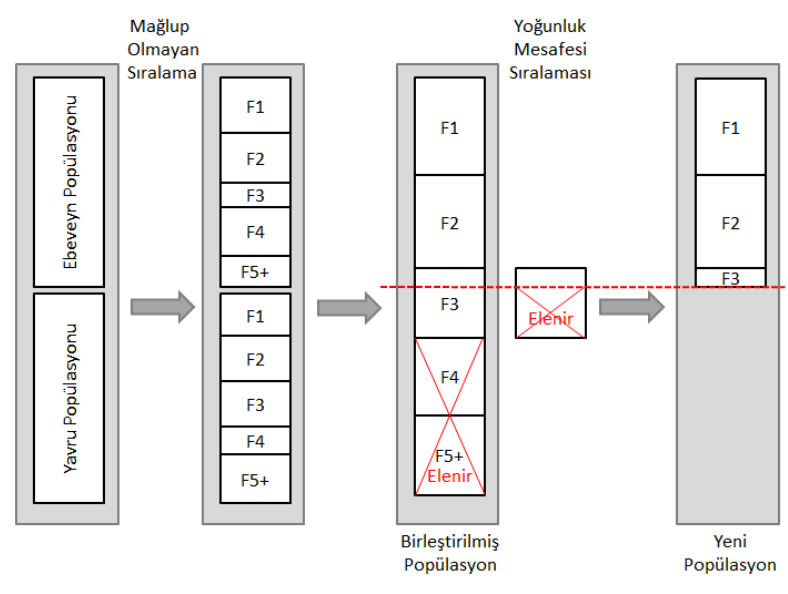

Şekil 2. NSGA-II elitist seçim prosedürü

\section{SAYISAL SONUÇLAR (NUMERICAL RESULTS)}

Önerilen algoritma Solomon'un $\mathrm{C} 1, \mathrm{R} 1$ ve $\mathrm{RC} 1$ veri setlerinin ilk beş problemine uygulanarak test edilmiştir [29]. Veri setleri müşterilerin coğrafik alandaki dağılım şekillerine göre farklılaşmaktadır. C1 setinde müşteriler depo etrafında kümelenmiş olarak, R1 setinde rastgele şekilde ve RC1 setinde yarı kümelenmiş yarı rastgele şekilde bulunmaktadır. Kullanılan veri setleri kısa zaman çizelgelerine sahiptir, araçların maksimum seyahat süreleri fazla uzun değildir. Problemlerde bir depo ve 100 müşteri bulunmaktadır. Müşteriler ve depoların konumları $(\mathrm{x}, \mathrm{y})$ koordinatları ile belirtilmiştir. Birbirleri arasındaki mesafeler Öklid uzaklığı ile hesaplanır ve elde edilen değer mesafe birimidir. Araçların 1 birim mesafeyi 1 birim zamanda gittikleri varsayıldığından elde edilen mesafe sonucu süre olarak da kullanılabilir. Müşterilerin talep miktarları veri setinde mevcuttur. Toplam 25 adet özdeş araç bulunmaktadır ve araçların kapasiteleri 200 birimdir. Her müşterinin servise en erken başlanılabileceği hazır olma zamanı ile en geç başlanılabileceği son zamanları ve servis süreleri belirtilmiştir.

Her bir problem seti için başlangıç popülasyonu oluşturma algoritmaları 1 ve 2, GA'ya uygulanarak 5'er adet bağımsız test çalıştırılıp karşılaştırma yapılmıştır. Önerilen uygulama Python dili kullanılarak geliştirilmiştir. Uygulama testi için i7 işlemci teknolojisine, $2.6 \mathrm{GHz}$ Turbo işlemci hızına ve $8 \mathrm{~GB}$ ram kapasitesine sahip bir bilgisayar kullanılmıştır. Uygulama için gerekli parametreler; popülasyon büyüklüğü, jenerasyon sayısı, maksimum araç sayısı, maksimum araç kapasitesi ve çaprazlama olasılığı ile mutasyon olasılığı parametreleri Tablo 4'te verilmiştir. Olasılık parametreleri literatürde kullanılan değerler temel alınarak belirlenmiştir. 
Tablo 4. Algoritma parametreleri

\begin{tabular}{|l|l|l|l|}
\hline PopülasyonBüyü̈klüğü & 200 & JenerasyonSayısı & 100 \\
\hline $\mathbf{P}_{\text {caprazlama }}$ & 0.7 & $\mathbf{P}_{\text {mutasyon }}$ & 0.1 \\
\hline Mak. Araç Sayısı & 25 & Mak. Kapasite & 200 \\
\hline
\end{tabular}

Tablo 5'te, kullanılan veri setindeki her problem için, algoritma 1 ve 2'yi kullanan GA'ların kat edilen toplam yola göre elde edilen en iyi çözümlerinin karşılaştırılması yapılmıştır. Bu karşılaştırmada ölçüt olarak en iyi çözümlerin toplam yol ve araç sayısı değerleri kullanılmıştır. Tablo 5'e göre algoritma 2'yi kullanan GA, algoritma 1'i kullanana göre bir araç daha az çözüm üretmeyi başarmıştır. Toplam yol açısından algoritma 2'yi kullanılan GA ile C1 setinde \%33'e, R1 setinde \%18'e ve RC1 setinde \%14'e kadar daha iyi sonuçlara ulaşılmıştır. Ayrıca RC102 probleminin literatürdeki en iyi sonucu olan 1554,75 birim toplam yol sonucu algoritma 2'yi kullanan GA ile aşılmıştır. Ancak literatürdeki bu sonuç 12 adet araç ile bulunmuştur. Toplam yol sonuçlarının genel toplamına göre algoritma 2'yi kullanan GA diğerine göre daha iyi performansa sahiptir.

Tablo 5. Algoritma 1 ve 2'yi kullanan GA'ların kat edilen toplam yola göre elde edilen en iyi çözümlerinin karşılaştırılması

\begin{tabular}{|c|c|c|c|c|c|c|}
\hline \multirow{2}{*}{$\begin{array}{c}\text { Veri } \\
\text { Seti }\end{array}$} & \multicolumn{2}{|c|}{$\begin{array}{c}\text { Algoritma 1'i } \\
\text { kullanan GA }\end{array}$} & \multicolumn{2}{c|}{$\begin{array}{c}\text { Algoritma 2'yi } \\
\text { kullanan GA }\end{array}$} & \multicolumn{2}{c|}{$\begin{array}{c}\text { Karşılaştırma } \\
\text { Oranı }\end{array}$} \\
\cline { 2 - 7 } & $\begin{array}{c}\text { Toplam } \\
\text { Yol }\end{array}$ & $\begin{array}{c}\text { Araç } \\
\text { sayısI }\end{array}$ & $\begin{array}{c}\text { Toplam } \\
\text { Yol }\end{array}$ & $\begin{array}{c}\text { Araç } \\
\text { sayıs }\end{array}$ & $\begin{array}{c}\text { Toplam } \\
\text { Yol }\end{array}$ & $\begin{array}{c}\text { Araç } \\
\text { sayıs }\end{array}$ \\
\hline C101 & 1168,052 & 12 & 892,6307 & 11 & $23,58 \%$ & $8,33 \%$ \\
C102 & 1146,565 & 11 & 954,622 & 11 & $16,74 \%$ & $0,00 \%$ \\
C103 & 1315,369 & 12 & 1079,744 & 11 & $17,91 \%$ & $8,33 \%$ \\
C104 & 1377,93 & 11 & 1187,427 & 11 & $13,83 \%$ & $0,00 \%$ \\
C105 & 1260,394 & 12 & 836,7574 & 10 & $33,61 \%$ & $16,67 \%$ \\
& & & & & & \\
R101 & 2180,591 & 22 & 1768,728 & 20 & $18,89 \%$ & $9,09 \%$ \\
R102 & 1783,374 & 17 & 1668,935 & 19 & $6,42 \%$ & $-11,76 \%$ \\
R103 & 1528,757 & 15 & 1486,471 & 16 & $2,77 \%$ & $-6,67 \%$ \\
R104 & 1151,352 & 11 & 1202,48 & 13 & $-4,44 \%$ & $-18,18 \%$ \\
R105 & 1720,662 & 17 & 1555,377 & 16 & $9,61 \%$ & $5,88 \%$ \\
& & & & & & \\
RC101 & 1890,23 & 17 & 1823,87 & 17 & $3,51 \%$ & $0,00 \%$ \\
RC102 & 1800,582 & 15 & $\mathbf{1 5 4 1 , 9 9 6}$ & $\mathbf{1 4}$ & $14,36 \%$ & $6,67 \%$ \\
RC103 & 1536,823 & 13 & 1516,749 & 14 & $1,31 \%$ & $-7,69 \%$ \\
RC104 & 1340,015 & 11 & 1295,02 & 12 & $3,36 \%$ & $-9,09 \%$ \\
RC105 & 1831,024 & 16 & 1780,302 & 16 & $2,77 \%$ & $0,00 \%$ \\
\hline
\end{tabular}

Tablo 6 iki algoritmanın araç sayısı açısından elde edilen en iyi çözümlerinin karşılaştırmasını sunmaktadır. Tablo 6 yapısal ve sayısal olarak Tablo 5 ile oldukça benzerdir. Ancak algoritma 1'i kullanan GA C101 ve R105 problemlerinde, algoritma 2'yi kullanan GA C103 ve R104 problemlerinde daha az araç ile çözüm elde etmeyi başarmıştır. Bu tabloda bu sonuçlar koyu renkte belirtilmiştir. Toplam yol sonuçlarının genel toplamına göre algoritma 2'yi kullanan GA diğerine göre daha iyi performansa sahiptir. 
Tablo 6. Algoritma 1 ve 2 'yi kullanan GA'ların araç sayısına göre elde edilen en iyi çözümlerinin karşılaş̧ırılması

\begin{tabular}{|c|c|c|c|c|c|c|}
\hline \multirow{2}{*}{$\begin{array}{c}\text { Veri } \\
\text { Seti }\end{array}$} & \multicolumn{2}{|c|}{$\begin{array}{c}\text { Algoritma 1'i } \\
\text { kullanan GA }\end{array}$} & \multicolumn{2}{c|}{$\begin{array}{c}\text { Algoritma 2'yi } \\
\text { kullanan GA }\end{array}$} & \multicolumn{2}{c|}{$\begin{array}{c}\text { Karşılaştırma } \\
\text { Oranı }\end{array}$} \\
\cline { 2 - 7 } & $\begin{array}{c}\text { Toplam } \\
\text { Yol }\end{array}$ & $\begin{array}{c}\text { Araç } \\
\text { sayıs }\end{array}$ & $\begin{array}{c}\text { Toplam } \\
\text { Yol }\end{array}$ & $\begin{array}{c}\text { Araç } \\
\text { sayıs }\end{array}$ & $\begin{array}{c}\text { Toplam } \\
\text { Yol }\end{array}$ & $\begin{array}{c}\text { Araç } \\
\text { sayısı }\end{array}$ \\
\hline C101 & $\mathbf{1 2 0 1 , 5 1 4}$ & $\mathbf{1 1}$ & 892,6307 & 11 & $25,71 \%$ & $0,00 \%$ \\
C102 & 1146,565 & 11 & 954,622 & 11 & $16,74 \%$ & $0,00 \%$ \\
C103 & 1315,369 & 12 & $\mathbf{1 0 9 4 , 2 7 9}$ & $\mathbf{1 0}$ & $16,81 \%$ & $16,67 \%$ \\
C104 & 1377,93 & 11 & 1187,427 & 11 & $13,83 \%$ & $0,00 \%$ \\
C105 & 1260,394 & 12 & 836,7574 & 10 & $33,61 \%$ & $16,67 \%$ \\
& & & & & & \\
R101 & 2180,591 & 22 & 1768,728 & 20 & $18,89 \%$ & $9,09 \%$ \\
R102 & 1783,374 & 17 & 1668,935 & 19 & $6,42 \%$ & $-11,76 \%$ \\
R103 & 1528,757 & 15 & 1486,471 & 16 & $2,77 \%$ & $-6,67 \%$ \\
R104 & 1151,352 & 11 & $\mathbf{1 2 2 5 , 6 6 3}$ & $\mathbf{1 2}$ & $-6,45 \%$ & $-9,09 \%$ \\
R105 & $\mathbf{1 7 4 6 , 4 4 8}$ & $\mathbf{1 6}$ & 1555,377 & 16 & $10,94 \%$ & $0,00 \%$ \\
& & & & & & \\
RC101 & 1890,23 & 17 & 1823,87 & 17 & $3,51 \%$ & $0,00 \%$ \\
RC102 & 1800,582 & 15 & 1541,996 & 14 & $14,36 \%$ & $6,67 \%$ \\
RC103 & 1536,823 & 13 & 1516,749 & 14 & $1,31 \%$ & $-7,69 \%$ \\
RC104 & 1340,015 & 11 & 1295,02 & 12 & $3,36 \%$ & $-9,09 \%$ \\
RC105 & 1831,024 & 16 & 1780,302 & 16 & $2,77 \%$ & $0,00 \%$ \\
\hline
\end{tabular}

Algoritma 1 ve 2'yi kullanan GA'ların kat edilen toplam yola göre elde edilen en iyi sonuçları arasında istatistiksel olarak anlamlı bir farklılığın olduğunu kanıtlamak amacıyla Minitab paket programı kullanılarak Bağımlı Örneklem t-Testi uygulanmıştır. Algoritmalar aynı problemlere uygulandıkları için algoritma sonuçlarının bağımlı değişkenler oldukları kabul edilmiştir. Parametrik testlerde değişken normal dağ 1 lım göstermelidir. Bu nedenle algoritma sonuçları arasındaki fark değerlerine Normallik testleri yapılmış ve normal dağılıma uydukları kanıtlanmıştır. Şekil 3'te algoritma sonuçlarının Bağımlı Örneklem t-Testi analiz sonucu görülmektedir. Buna göre, \%99 güven aralığında, algoritma 1'i kullanan GA sonuçları algoritma 2'yi kullanan GA sonuçlarına göre ileri düzeyde yüksek bulunmuştur.

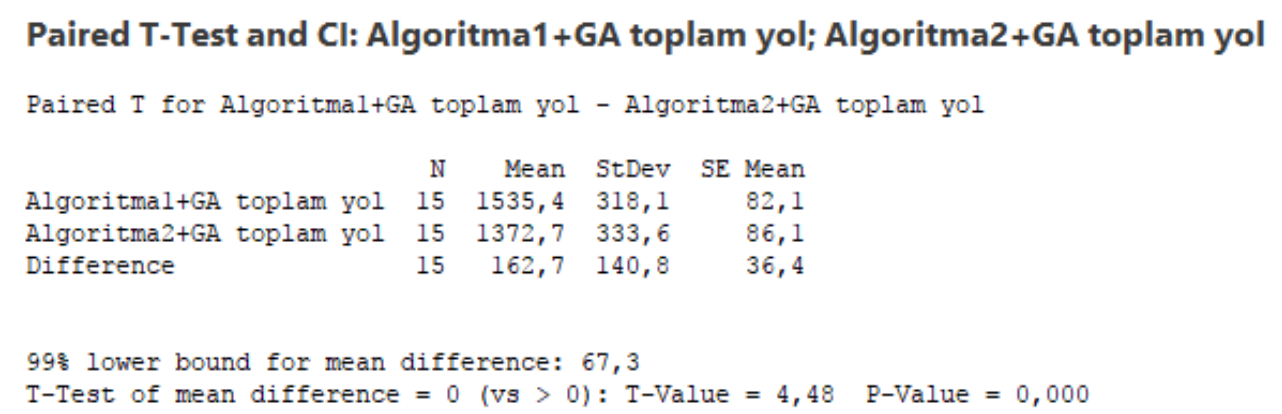

Şekil 3. Minitab çıtktısı

\section{SONUÇ (CONCLUSION)}

ZPARP belirli zaman aralıklarında hizmet görmesi gereken müşterilere hizmet veren araçların bir depodan başlayan ve orada biten rotalarının çizilmesi problemidir. Bu çalışmada toplam yolu ve araç sayısını minimize etmek amaç fonksiyonları olarak belirlenmiş ve ZPARP için çok amaçlı GA çözümü önerilmiştir. GA'da bireylerin değerlendirilmesi, sıralanması ve seçilmesi işlemlerinde çok amaçlı çözüm yöntemlerinden NSGA-II kullanılmıştır. Önerilen GA başlangıç popülasyonu oluşturma aşamasında yapısal sezgisel yöntemlerden biri olan süpürme algoritması kullanılarak melezleştirilmiştir. En yakın komşu algoritması temel alınarak oluşturulan algoritma 1'i kullanan GA ve süpürme algoritması temel 
alınarak oluşturulan algoritma 2'yi kullanan GA literatürdeki bir veri problemine uygulanmış ve sonuçları karşılaştırılmıştır. Algoritma 2'yi kullanan GA ile toplam yola göre C1 setinde \%33'e, R1 setinde \%18'e ve RC1 setinde \%14'e kadar daha iyi sonuçlara ulaşılmıştır. Araç sayısı kriterine göre sonuçlar karşılaştırıldığında anlamlı bir fark görülmemekle beraber, algoritma 2'yi kullanan GA daha az araç sayısıyla çözüme ulaşmıştır. Süpürme algoritmasıyla melezleştirilen GA Bağımlı Örneklem t-Testi analizi sonuçlarına göre daha iyi performansa sahiptir.

Gelecek çalışmalarda bu çalışmada kullanılan çaprazlama ve mutasyon operatörleri geliştirilerek ve daha etkili parametreler belirlenerek test problemleri çözülüp literatürde bulunan sonuçlarla karşılaştırılabilir veya farklı amaç fonksiyonları belirlenerek alternatif bir çalışma yapılabilir.

\section{KAYNAKLAR (REFERENCES)}

[1] J. K. Lenstra, A. H. G. Kan, Complexity of vehicle routing and scheduling problems. Networks, 11:2 (1981) 221-227.

[2] S. Çolak, H. Güler, Dağıtım rotaları optimizasyonu için meta sezgisel bir yaklaşım. Gazi Üniversitesi İktisadi ve İdari Bilimler Fakültesi Dergisi, 11 (2009) 171-189.

[3] Y. Şahin, A. Eroğlu, Kapasite kısıtlı araç rotalama problemi için metasezgisel yöntemler: Bilimsel yazın taraması. Süleyman Demirel Üniversitesi İ.İ.B.F. Dergisi, 19:4 (2014) 337-355.

[4] G. Laporte, The vehicle routing problem: An overview of exact and approximate algorithms. European journal of operational research, 59:3 (1992) 345-358.

[5] N. A. El-Sherbeny, Vehicle routing with time windows: An overview of exact, heuristic and metaheuristic methods. Journal of King Saud University-Science, 22:3 (2010) 123-131.

[6] P. Toth, D. Vigo (Eds.), Vehicle routing: problems, methods, and applications, Society for Industrial and Applied Mathematics, 2014.

[7] B. M. Baker, M. A. Ayechew, A genetic algorithm for the vehicle routing problem. Computers \& Operations Research, 30 (2003) 787-800.

[8] D. Mester, O. Braysy, Active-guided evolution strategies for large-scale capacitated vehicle routing problems. Computers \& Operations Research, 34:10 (2007) 2964-2975.

[9] J. Berger, M. Barkaoui, A parallel hybrid genetic algorithm for the vehicle routing problem with time windows. Computers \& Operations Research, 31:12 (2004) 2037-2053.

[10] S. R. Thangiah, K E. Nygard, P. L. Juell, Gideon: A Genetic Algorithm System for Vehicle Routing With Time Windows, 7th IEEE Conference on Artificial Intelligence Applications, Miami BeachFlorida, 322-325, 24-28 Şubat, 1991.

[11] M. F. Ibrahim, I. Masudin, T. E. Saputro, A hybrid genetic algorithm implementation for vehicle routing problem with time windows. Jurnal Ilmiah Teknik Industri, 14:2 (2016) 196-204.

[12] C. Prins, A simple and effective evolutionary algorithm for the vehicle routing problem. Computers \& Operations Research, 31:12 (2004) 1985-2002.

[13] Y. Chang, L. Chen, Solve the vehicle routing problem with time windows via a genetic algorithm. Discrete and continuous dynamical systems supplement, (2007) 240-249.

[14] B. Ombuki, B. J. Ross, F. Hanshar, Multi-objective genetic algorithms for vehicle routing problem with time windows. Applied Intelligence, 24:1 (2006) 17-30.

[15] S. A. Haddadene, N. Labadie, C. Prodhon, NSGAII enhanced with a local search for the vehicle routing problem with time windows and synchronization constraints. IFAC-PapersOnLine, 49:12 (2016) 11981203. 
[16] K. C. Tan, Y. H. Chew, L. H. Lee, A hybrid multiobjective evolutionary algorithm for solving vehicle routing problem with time windows. Computational Optimization and Applications, 34:1 (2006) 115151.

[17] A. Mungwattana, T. Manisri, K. Charoenpol, G. K. Janssens, A solution for the bi-objective vehicle routing problem with the windows using local search and genetic algorithms. International Journal for Traffic and Transport Engineering, 6:2 (2016) 149-158.

[18] K. Ghoseiri, S. F. Ghannadpour, Multi-objective vehicle routing problem with time windows using goal programming and genetic algorithm. Applied Soft Computing, 10:4 (2010) 1096-1107.

[19] A. Garcia-Najera, J. A. Bullinaria, An improved multi-objective evolutionary algorithm for the vehicle routing problem with time windows. Computers \& Operations Research, 38:1 (2011) 287-300.

[20] W. K. Ho, J. C. Ang, A. Lim, A hybrid search algorithm for the vehicle routing problem with time windows. Int. J. Artif. Intell. Tools, 10:3 (2001) 431-449.

[21] M. M. Solomon, J. Desrosiers, Survey Paper-Time Window Constrained Routing and Scheduling Problems. Transportation Science 22:1 (1988) 1-13.

[22] B. E. Gillett, L. R. Miller, A heuristic algorithm for the vehicle dispatch problem. Oper. Res., 22 (1974) 340-349.

[23] U. Tül, A. Tuncer, Genetik Algoritma ile Akıllı Test Sayfası Oluşturma. GU J Sci, Part C, 5:4 (2017) 27-34.

[24] F. K1lı̧, M. Gök, A Benchmark Proposal for Route-Planning Of Urban Bus Service, 4th Eastern European Regional Conference on the Engineering of Computer Based Systems, Bruno-Çek Cumhuriyeti, 134-137, 27-28 Ağustos, 2015.

[25] K. Deb, A. Pratap, S. Agarwal, T. A. M. T. A. Meyarivan, A fast and elitist multiobjective genetic algorithm: NSGA-II. IEEE Trans. Evol. Comput., 6:2 (2002) 182-197.

[26] K. Deb, Multi-Objective Optimization Using Evolutionary Algorithms. Vol. 16, John Wiley \& Sons, 2001.

[27] F. A. Fortin, D. Rainville, M. A. G. Gardner, M. Parizeau, C. Gagné, DEAP: Evolutionary algorithms made easy. The Journal of Machine Learning Research, 13:1 (2012) 2171-2175.

[28] A. Seshadri, A Fast Elitist Multiobjective Genetic Algorithm: NSGA-II. MATLAB Central, 182, 2006.

[29] M. M. Solomon, Algorithms for the vehicle routing and scheduling problems with time window constraints. Oper. Res., 35:2 (1987) 254-265. 